\title{
How Can I Share My Work? A Review of the Open Access Policies of IS Journals
}

\author{
Cathal Doyle \\ Victoria University of Wellington, New Zealand \\ cathal.doyle@,vuw.ac.nz
}

\begin{abstract}
We conducted a literature review of the open access (OA) policies of IS journals which indicates they are adapting to the evolving research landscape that incorporates open science practices. And just as the IS journals are changing, IS researchers need to change too. However, while different entities can offer guidance, help, and nudges to authors to try and promote the practice of $O A$, it will not become a norm until the IS researchers themselves adopt it into their own practices. That is, they need to reconsider their practices by moving beyond the academic paper as the only output of a research project and consider how other research components they create can be made freely available as an open artefact. In doing so, not only can they increase their research outputs but also develop their academic profile while making opportunities for new projects and collaborations.
\end{abstract}

\section{Introduction}

Open science (OS) refers to making scientific knowledge freely available to the public, where open practices are becoming a requirement to be eligible for funding from most competitive funding schemes. One open practice these schemes often insist on is that of open access (OA), which can be defined as "online, peer-reviewed scholarly outputs, which are free to read, with limited or no copyright and licensing restrictions" [11, p.1]. But while such funding schemes, as well as libraries, universities, and governments, try to promote OA by guiding, helping, or nudging authors, it will not become a norm until the authors themselves adopt it into their own practices [17]. Trying to change this behaviour is not so straight forward as many are unsure of the policies around making their work freely available but it is important for them to understand the options available to them.

For example, currently authors look at OA from an article only perspective, despite the definition above stating "scholarly outputs". However, research projects create a lot more artefacts than just an article, which includes problem statements; research questions; literature reviews; hypothesis; a research methodology; datasets; frameworks; software; and peer reviews, to name a few. What is not immediately obvious for authors is knowing what they can share from these artefacts, where they can share them, and the value in sharing them. In order to encourage OA practices, Suber [17] suggests four-author centric strategies: 1. Educate authors about OA; 2. Help authors provide OA to their work; 3. Remove disincentives for authors to provide OA to their work; and 4. Create incentives for authors to provide OA to their work.

In this study, we address three of these strategies from an IS research perspective. First, we explain the components of OA which consist of journal types; manuscript types; the route to making a manuscript available; and develop an understanding of the relationship between copyright and licenses and OA. This can help educate IS researchers about OA. Second, we conduct a review of the OA policies of IS journals to develop an understanding of what they allow authors to practice in terms of OA. This can help IS researchers make informed decisions when considering making their manuscripts freely available. Third, we discuss the value of being more open which describes how practicing OA can be used by IS researchers to improve the impacts of their research outputs, help develop their academic profile, and address the issue of financial concerns that is often raised. We first introduce the components of OA in the next section.

\section{Components of Open Access}

Open access (OA) is made up of several components including the journal type; manuscript type; the route; and copyright and licenses. These can be fit together in different ways by the author of an article in order to make their research freely available. Each are explained in more detail over the following sections starting with journal type. 


\subsection{Journals}

The first element are the types of journals that are available for authors to publish in. There are four which consist of open access journals; non-open access journals; hybrid journals; and predatory journals. In terms of open access journals, they make their articles freely available online, which can be accessed by anyone [14]. Non-open access journals (sometimes referred to as traditional journals) are subscription based, where articles can only be accessed either by being subscribed or sometimes paying a one-off payment for a specific article [4]. Then there are hybrid journals, which still have a subscription based model but offer some open access articles [3]. Here, open access content can be freely accessed by anyone but non-open access content is behind a payment of some form. Then there are predatory journals $[1,7]$. These try to dupe researchers into paying a fee to publish their research quickly [1].

\subsection{Manuscripts}

An article usually goes through a number of lifecycles before the final version is published [2] which results in several versions existing. This goes from a working paper, to the author's original manuscript, to the author's accepted manuscript, through to the version of record. A Working Paper (WP) is any article version that the author makes available online [2] that has been entirely prepared by them with no input from a publisher [5]. In such cases, they may be looking for some pre- open peer review on their work to date. This is followed by the Author's Original Manuscript (AOM) which is the copy submitted to the journal which has not yet been peer reviewed [21] and thus still has had no input from a publisher [5]. Both the WP and AOM can be referred to as a pre-print $[2,22]$. Then there is the Author's Accepted Manuscript (AAM) that has been peer reviewed and contains the author's changes which have been accepted by the editor [21]. This has an input from a publisher but is still author prepared as copyediting and final markup has not yet been done [5] Lastly, there is the Version of Record (VoR) which is the copy-edited and typeset version that gets published [21] which is created by the publisher [5]. Both the AAM and VoR can be referred to as a postprint $[2,5$, 22].

\subsection{Routes}

2.3.1. Green Open Access. Green OA means "the publisher locks the final published form of the paper behind a paywall, but the author takes steps to ensure that it's freely available elsewhere" [23]. It is also referred to as self-archiving [19]. It allows the author to archive their article even if they publish in a nonopen access journal [8]. There are three ways that an author can do this: they can upload it to their own personal website or institutional website; upload it to an institutional repository; and upload it to a subject repository $[2,19]$. Here, institutional repositories try to capture all the research from the scholars in a given institution $[2,18]$. While a subject repository tries to capture all the research in a given field [18] such as arXiv for physics or PubMed Central for medicine. An author can make their preprint article (WP and AOM) available at any time to any repository, just keep in mind some journals may not publish an article that has previously circulated as a preprint (known as the Ingelfinger Rule and is largely in decline [15]. Then, depending on the permission from the journal, authors may also be able to upload their postprint article (AAM) in non-commercial repositories. However, there may be an embargo period on when authors can upload their article, and this can differ across where they can upload it. Further, journals often require that authors acknowledge the published version by inserting a clause about where the final version is, and providing a link to it [5]. In terms of the VoR, journals generally do not permit the archiving of this version, although this is not always the case.

2.3.2. Gold Open Access. Gold OA means "the publisher, which creates the final published form of the paper (i.e. usually a PDF) makes that final published form freely available." [23]. Here, open access journals and hybrid journals provide free access to the VoR immediately upon publication without restrictions to anyone [24]. This is made possible in two ways. The first is referred to as diamond OA, which is a form of gold OA where there is no author fee for the publication [22]. The second involves an article processing charge (APC) where there is an author fee. These charges are either paid by the author, their institution, or their funding body [3] and must be paid before the article is published. It should also be noted that some institutions and funding bodies have made agreements with publishers in advance which involves a fee but allows the author to take the gold OA route.

\subsection{Copyright and Licenses}

When considering green and gold OA, the author is considering the venue for their article [18]. However, another element to consider for these routes is the level 
of access that is provided to them. While initial definitions of OA did not incorporate this, Suber [16] suggests gratis and libre open access. Here, gratis means users can access the article with price barriers removed but they can only read it [16] while reuse is restricted [22]. Libre means removal of price barriers and at least some permission barriers [16], meaning user's can not only read the article for free but also share and reuse it depending on the license being used $[10,22]$. Both green $\mathbf{O A}$ and gold $\mathbf{O A}$ can be gratis or libre (libre includes gratis) [16].

Copyright is defined as the "exclusive right given to the creator of a creative work to reproduce the work, usually for a limited time" [25]. Here, the copyright of an article is with the author until they decide to publish it. In a traditional publishing route, the author usually transfers the copyright exclusively to the publisher [26]. They then have a license which explains what users may and may not do with the article [18]. For example, they may grant permission for green OA, allowing the author to self-archive the AAM. While this approach remains similar in OA, there are some notable differences. First, if the gold access route is taken, the author usually retains the copyright and grants a non-exclusive license to the publisher to distribute the work [26]. Then, the author can adopt a license that explains what users may and may not do with the article. While they can create their own license, it is recommended that they use an open license $[18,26]$. In particular, it is recommended (and is the most common) that publishers and authors choose a Creative Commons (CC) license [18, 26].

There are six main $\mathbf{C C}$ licenses to choose from, which are based on a combination of four conditions: 1. Attribution (BY) where all CC licenses require that others who use your work in any way must give you credit the way you request, but not in a way that suggests you endorse them or their use; 2. ShareAlike (SA) which lets others copy, distribute, display, perform, and modify your work, as long as they distribute any modified work on the same terms; 3. NonCommercial (NC) which lets others copy, distribute, display, perform, and modify and use your work for any purpose other than commercially; and 4. NoDerivatives (ND) let others copy, distribute, display and perform only original copies of your work. Any of these can be voided with explicit permission from the copyright holder. The CC licenses then apply these in different combinations, which are presented in Table 1.

As can be seen from Table 1, the CC licenses create "some-rights-reserved" copyrights rather than "all-rights reserved" copyrights [18]. They also get stricter as they go from top to bottom. That is to say, the CC BY license is the most open, where it allows users (both commercial and non-commercial) to distribute, remix, tweak, and build upon your work, so long as they credit the author. This is in stark contrast to the CC BY-NC-ND license which only allows noncommercial users to view the article and share it with others.

Table 1: Creative commons licenses explanation

\begin{tabular}{|c|c|}
\hline CC License & Explanation \\
\hline $\begin{array}{l}\text { Attribution } \\
\text { (CC BY) }\end{array}$ & $\begin{array}{l}\text { This license lets others distribute, } \\
\text { remix, tweak, and build upon your } \\
\text { work, even commercially, as long } \\
\text { as they credit you for the original } \\
\text { creation. }\end{array}$ \\
\hline $\begin{array}{l}\text { Attribution } \\
\text { ShareAlike } \\
\text { (CC BY-SA) }\end{array}$ & $\begin{array}{l}\text { This license lets others remix, } \\
\text { tweak, and build upon your work } \\
\text { even for commercial purposes, as } \\
\text { long as they credit you and license } \\
\text { their new creations under the } \\
\text { identical terms. }\end{array}$ \\
\hline $\begin{array}{l}\text { Attribution- } \\
\text { NoDerivs } \\
\text { (CC BY-ND) }\end{array}$ & $\begin{array}{l}\text { This license lets others reuse the } \\
\text { work for any purpose, including } \\
\text { commercially; however, it cannot } \\
\text { be shared with others in adapted } \\
\text { form, and credit must be provided } \\
\text { to you. }\end{array}$ \\
\hline $\begin{array}{l}\text { Attribution- } \\
\text { NonCommercial } \\
\text { (CC BY-NC) }\end{array}$ & $\begin{array}{l}\text { This license lets others remix, } \\
\text { tweak, and build upon your work } \\
\text { non-commercially, and although } \\
\text { their new works must also } \\
\text { acknowledge you and be non- } \\
\text { commercial, they don't have to } \\
\text { license their derivative works on } \\
\text { the same terms. }\end{array}$ \\
\hline $\begin{array}{l}\text { Attribution- } \\
\text { NonCommercial- } \\
\text { ShareAlike } \\
\text { (CC BY-NC-SA) }\end{array}$ & $\begin{array}{l}\text { This license lets others remix, } \\
\text { tweak, and build upon your work } \\
\text { non-commercially, as long as they } \\
\text { credit you and license their new } \\
\text { creations under the identical terms. }\end{array}$ \\
\hline $\begin{array}{l}\text { Attribution- } \\
\text { NonCommercial- } \\
\text { NoDerivs } \\
\text { (CC BY-NC-ND) }\end{array}$ & $\begin{array}{l}\text { This license is the most restrictive } \\
\text { of our six main licenses, only } \\
\text { allowing others to download your } \\
\text { works and share them with others } \\
\text { as long as they credit you, but they } \\
\text { can't change them in any way or } \\
\text { use them commercially. }\end{array}$ \\
\hline
\end{tabular}

Both the Open Access Scholarly Publishers Association (OASPA) and the SPARC Europe Seal of 
Approval recommend the CC BY license for publishing OA [18]. Depending on which license is applied, they offer different flavours of libre OA. For example, CC BY-ND does allow commercial use but does not allow derivative works, whereas CC BY-NC allows derivative works only by non-commercial users. It should be noted that a problem with the noncommercial use is that a definition of what it actually is remains quite fuzzy [26].

With this understanding of the components of $\mathrm{OA}$, we wish to conduct a review of IS journals in order to identify the types of journals that are available in the discipline; the routes they offer for OA, including what manuscripts authors can archive and where they can do so; and the copyright and licenses that are are offered when doing so. We will conduct a review of the OA policies of twenty IS journals (where they have one) based on the components from above and also any that emerge during the review. The methodology is presented next and is followed by the findings.

\section{Methodology}

For this OA policy review, we've adapted the literature review framework that we applied in our other OS study [6] to fit with searching IS journal websites as opposed to journal articles. We follow four phases: 1. Select the Source; 2. Search Strategy; 3. Coding Schemes; and 4. Journal Website Review. Starting with 1. Selecting the Sources: the researcher(s) must specify the domain of interest for their research, and then identify relevant sources for which articles can be obtained for the literature review. The domain of interest for this research focused on the OA policies of IS journals. We identified twenty journals including the senior scholar basket of eight journals and a further twelve A ranked journals as presented in Table 2.

2. Search Strategy: The next stage involves searching the selected sources. As the focus of the review was on OA policies of IS journals, it was determined that we would search their websites for information on said policies. A number of key terms were identified such as "Open Access", "Gold Open Access", "Green Open Access" and "Open Science" where each were used on the IS journal websites to determine their policies. Often, the journal websites linked to the publisher's main website to describe their OA policies. 3. Coding Schemes: The researcher(s) need to determine what is going to be captured from the review. For this study, a hybrid approach to developing the coding scheme was adopted. This involved using the components of OA from above such as "Journal Type"; "Manuscript Type"; "Routes"; and
"Copyright and Licenses" as well as some emerging concepts such as the journals having their own specific programs for publishing gold OA. Presented in Table 3 is the coding scheme we applied when reviewing each journal website.

Table 2: IS journals

\begin{tabular}{|c|c|}
\hline Journal & Acronym \\
\hline European Journal of Information Systems & EJIS \\
\hline Information Systems Journal & ISJ \\
\hline Information Systems Research & ISR \\
\hline $\begin{array}{l}\text { Journal of the Association of Information } \\
\text { Systems }\end{array}$ & JAIS \\
\hline Journal of Information Technology & JIT \\
\hline $\begin{array}{l}\text { Journal of Management Information } \\
\text { Systems }\end{array}$ & JMIS \\
\hline Journal of Strategic Information Systems & JSIS \\
\hline MIS Quarterly & MISQ \\
\hline $\begin{array}{l}\text { Australasian Journal of Information } \\
\text { Systems }\end{array}$ & AJIS \\
\hline $\begin{array}{l}\text { Communication of the Association for } \\
\text { Information Systems }\end{array}$ & CAIS \\
\hline Decision Support Systems & DSS \\
\hline Data and Knowledge Engineering & $\mathrm{DKE}$ \\
\hline Electronic Markets & EM \\
\hline $\begin{array}{l}\text { International Journal of Electronic } \\
\text { Commerce }\end{array}$ & IJEC \\
\hline Scandinavian Journal of IS & SJIS \\
\hline $\begin{array}{l}\text { Journal of the Operational Research } \\
\text { Society }\end{array}$ & JORS \\
\hline Journal of Computer Information Systems & JCIS \\
\hline Behaviour and Information Technology & $\mathrm{BIT}$ \\
\hline Management Science & MS \\
\hline Decision Sciences & DS \\
\hline
\end{tabular}


Table 3: Coding scheme

\begin{tabular}{|c|c|}
\hline Code & Explanation \\
\hline OA Policy & Does the journal have an OA policy? \\
\hline Journal Type & $\begin{array}{l}\text { Is it an OA journal, hybrid journal, } \\
\text { or non-OA journal? }\end{array}$ \\
\hline \multicolumn{2}{|r|}{ Gold OA } \\
\hline Availability & Is gold OA available? \\
\hline Program Name & $\begin{array}{l}\text { If so, is there a specific program } \\
\text { dedicated to it? }\end{array}$ \\
\hline License & $\begin{array}{l}\text { What creative commons license do } \\
\text { they allow? }\end{array}$ \\
\hline \multicolumn{2}{|r|}{ Green OA } \\
\hline Availability & Is green OA available? \\
\hline Version & $\begin{array}{l}\text { If so, what version of the manuscript } \\
\text { can be shared? }\end{array}$ \\
\hline License & $\begin{array}{l}\text { What creative commons license do } \\
\text { they allow? }\end{array}$ \\
\hline Location & $\begin{array}{l}\text { Where can you deposit the } \\
\text { manuscript (personal website, } \\
\text { institutional repository, and/or } \\
\text { subject repository)? }\end{array}$ \\
\hline Embargo & $\begin{array}{l}\text { Is there an embargo on when an } \\
\text { author can deposit a manuscript? }\end{array}$ \\
\hline
\end{tabular}

4. Journal Website Review: Once the coding scheme was refined after an initial review of a number of IS journal websites, it was used to review all twenty journal websites. The data set can be accessed here: https://www.doi.org/10.17605/OSF.IO/5YJGP. This data was then analysed and the findings are discussed in the next section which provides an understanding of OA policies in these IS journals.

\section{Findings}

There are a number of findings that can be observed. The first is that the vast majority of journals (19 out of 20) offer some form of OA policy. MISQ is the only journal that does not openly state on their website what their OA policy is (even though it is available as some articles are offered as OA). The reason for such a majority is that most of the journals are owned by large publishers who have begun to implement OA policies across all their journals. These policies are then adapted in some form by the individual IS journals.

Further, the majority of journals are hybrid journals, with 16 in total (EJIS, ISJ, ISR, JIT, JMIS, JSIS, MISQ, DSS, DKE, EM, IJEC, JORS, JCIS, BIT, $\mathrm{MS}$, and DS). That is to say, they are mainly traditional journals but the author has the option of publishing their article as OA. There are two non-open access journals (JAIS and CAIS) where they do not offer the author an opportunity to publish their article as gold OA. There are one definitive OA journal. AJIS is diamond OA, where they publish all articles as OA free of charge to the author, and they are the only journal to appear on the Directory of Open Access Journals (https://doaj.org/). SJIS may be an OA journal as they make all their articles freely available but it is not immediately obvious if the authors must pay for this, and they do not appear in the Directory of Open Access Journals.

In terms of the routes that an author can take, the majority offer both green OA and gold OA. 18 of the 20 journals address green OA in some form (AJIS does not as they offer diamond OA and MISQ does not address it at all). As shown in Table 4, 13 of the 20 journals allow the author to upload their AOM manuscript to their own personal website or institutional/subject repository without an embargo. 17 of the 20 journals also allow an author to make their AAM available. However, there are differences in terms of embargos. For example, 15 journals allow the author to upload their AAM manuscript to their personal website after acceptance (EJIS, ISR, JAIS, JIT. JMIS, JSIS, CAIS, DSS, DKE, EM, IJEC, JORS, JCIS, BIT, MS), while 2 have some form of embargo (ISJ after 12 months and DSF after 24 months). In terms of an institutional/subject repository, 5 journals allow the author to upload them after acceptance (ISR, JAIS, JIT, CAIS, and MS). The others have some form of embargo ranging from 12 to 24 months after publication. As expected, the vast majority do not allow for the uploading of the VoR manuscript except for 3 journals. JAIS and CAIS allow the author to upload their VoR to both their personal website and institutional/subject repository after publication, while MISQ allows it five years after publication.

18 of the 20 journals allow the author to take the gold OA route (MISQ do not explicitly state their price or license types) as shown in Table 5. The vast majority charge for this, ranging in prices from $\$ 1300$ $\$ 4000$ USD (pre-tax). As noted earlier, AJIS is the only one that offers this free of charge to the author but they are restricted in terms of the CC license that they can apply (only option is CC BY-ND). All the other 
Table 4: Green route options in IS journals

\begin{tabular}{|c|c|c|c|c|c|c|}
\hline \multirow[b]{2}{*}{ Journal } & \multicolumn{2}{|c|}{ AOM } & \multicolumn{2}{|c|}{ AAM } & \multicolumn{2}{|c|}{ VoR } \\
\hline & PW & Repo & PW & Repo & PW & Repo \\
\hline EJIS & Immediately & Immediately & $\mathrm{AA}$ & 12 months & Not allowed & Not allowed \\
\hline ISJ & Immediately & Immediately & 12 months & 12 months & Not allowed & Not allowed \\
\hline ISR & & & $\mathrm{AA}$ & $\mathrm{AA}$ & Not allowed & Not allowed \\
\hline JAIS & & & $\mathrm{AA}$ & $\mathrm{AA}$ & AP & $\mathrm{AP}$ \\
\hline JIT & Immediately & Immediately & $\mathrm{AA}$ & 0 months & Not allowed & Not allowed \\
\hline JMIS & Immediately & Immediately & $\mathrm{AA}$ & 18 months & Not allowed & Not allowed \\
\hline JSIS & Immediately & Immediately & $\mathrm{AA}$ & 24 months & Not allowed & Not allowed \\
\hline MISQ & & & & & 5 years & 5 years \\
\hline CAIS & & & $\mathrm{AA}$ & $\mathrm{AA}$ & $\mathrm{AP}$ & $\mathrm{AP}$ \\
\hline \multicolumn{7}{|l|}{ AJIS } \\
\hline DSS & Immediately & Immediately & $\mathrm{AA}$ & 24 months & Not allowed & Not allowed \\
\hline DKE & Immediately & Immediately & $\mathrm{AA}$ & 24 months & Not allowed & Not allowed \\
\hline EM & Immediately & Immediately & $\mathrm{AA}$ & 12 months & Not allowed & Not allowed \\
\hline IJEC & Immediately & Immediately & $\mathrm{AA}$ & 18 months & Not allowed & Not allowed \\
\hline \multicolumn{7}{|l|}{ SJIS } \\
\hline JORS & Immediately & Immediately & $\mathrm{AA}$ & 12 months & Not allowed & Not allowed \\
\hline JCIS & Immediately & Immediately & $\mathrm{AA}$ & 12 months & Not allowed & Not allowed \\
\hline BIT & Immediately & Immediately & $\mathrm{AA}$ & & Not allowed & Not allowed \\
\hline MS & & & $\mathrm{AA}$ & $\mathrm{AA}$ & Not allowed & Not allowed \\
\hline DSJ & Immediately & Immediately & 24 months & 24 months & Not allowed & Not allowed \\
\hline
\end{tabular}

$\mathrm{PW}=$ Personal Website

Repo = Institute/Subject Repository

$\mathrm{AA}=$ After Acceptance

$\mathrm{AP}=$ After Publication 
journals that offer the gold OA route also use the CC licenses, and give the author a choice. ISR and MS are the most generous, where the author can choose from the six licenses in Table 1. The majority also offer the opportunity to use CC-BY, which is the most open CC license available. Strangely, as shown in Table 5 a lot of journals offer the author the choice between the most open CC license and the most restrictive (EJIS, JMIS, JSIS, DSS, DKE, IJEC, JORS, JCIS, and BIT).

Table 5: Gold route prices and possible creative commons licenses

\begin{tabular}{|c|c|c|c|c|c|c|c|}
\hline & & \multicolumn{6}{|c|}{ Creative Commons Licenses } \\
\hline Journal & Price & $\begin{array}{l}\text { CC } \\
\text { BY }\end{array}$ & $\begin{array}{c}\text { CC } \\
\text { BY } \\
- \\
\text { SA }\end{array}$ & $\begin{array}{c}\text { CC } \\
\text { BY } \\
- \\
\text { ND }\end{array}$ & $\begin{array}{c}\text { CC } \\
\text { BY } \\
- \\
\text { NC }\end{array}$ & $\begin{array}{c}\text { CC } \\
\text { BY } \\
- \\
\text { NC } \\
- \\
\text { SA }\end{array}$ & $\begin{array}{c}\text { CC } \\
\text { BY } \\
- \\
\text { NC } \\
- \\
\text { ND }\end{array}$ \\
\hline EJIS & $\$ 2995$ & $\bar{X}$ & & & & & $\mathrm{X}$ \\
\hline ISJ & $\$ 4000$ & $\mathrm{X}$ & & & $\bar{X}$ & & $\mathrm{X}$ \\
\hline ISR & $\$ 3000$ & $X$ & $\mathrm{X}$ & $X$ & $X$ & $X$ & $\mathrm{X}$ \\
\hline JAIS & & & & & & & \\
\hline JIT & $\$ 3000$ & $X$ & & $\mathrm{X}$ & $\mathrm{X}$ & & $\mathrm{X}$ \\
\hline JMIS & $\$ 2995$ & $X$ & & & & & $\mathrm{X}$ \\
\hline JSIS & $\$ 2520$ & $\bar{X}$ & & & & & $\mathrm{X}$ \\
\hline MISQ & & & & & & & \\
\hline CAIS & & & & & & & \\
\hline AJIS & Free & & & & $\mathrm{X}$ & & \\
\hline DSS & $\$ 1300$ & $\bar{X}$ & & & & & $\mathrm{X}$ \\
\hline DKE & $\$ 3100$ & $X$ & & & & & $\mathrm{X}$ \\
\hline EM & $\$ 2750$ & $\bar{X}$ & & & & & \\
\hline IJEC & $\$ 2995$ & $\mathrm{X}$ & & & & & $\mathrm{X}$ \\
\hline SJIS & Free & & & & & & \\
\hline JORS & $\$ 2995$ & $\mathrm{X}$ & & & & & $\bar{X}$ \\
\hline JCIS & $\$ 2995$ & $\bar{X}$ & & & & & $\bar{X}$ \\
\hline BIT & $\$ 2995$ & $\mathrm{X}$ & & & & & $\mathrm{X}$ \\
\hline $\mathrm{MS}$ & $\$ 3000$ & $\mathrm{X}$ & $X$ & $X$ & $\mathrm{X}$ & $X$ & $\mathrm{X}$ \\
\hline DSJ & $\$ 2500$ & & & & $\mathrm{X}$ & & $\mathrm{X}$ \\
\hline
\end{tabular}

\section{Discussion}

It's great that the journals of the IS discipline are engaging with OS, and OA in particular, making it possible for authors to have different options. This is important as more institutions, and funding bodies, require any articles that their employees or fundees write to be made freely available to the public. It's important that researchers acknowledge that they are not funded by taxpayers to just further academic discussion and debate but are there to produce and disseminate new knowledge that should help enrich society [26]. We would encourage authors to not only familiarise themselves with $\mathrm{OA}$, the routes available, and the discussions around copyright, but they should engage with the practices. As shown in Table 4 and Table 5, they have many opportunities to make their manuscripts freely available and should do so. If you cannot afford gold OA, the vast majority of IS journals offer the green OA route, which involves a few additional steps to make it happen.

However, just as the journals are changing, researchers may need to change also. That is, researchers need to reconsider their practices in relation to how they conduct and share their research. They have opportunities to disseminate different artefacts that are generated during a research project, and we argue they should engage in such practices. The traditional scientific process is one of identifying a research problem, setting research questions, gathering, analysing and interpreting data, and publishing the results (often in an academic outlet). However, with the advent of information technology, and the internet, the expectations for conducting, publishing, and communicating research has changed drastically, where researchers are no longer restricted by this traditional scientific process. Instead, they have started to adopt more open approaches to their research projects, which has seen OS growing in prominence in recent years and is challenging this traditional scientific process used in information systems (IS) research also.

First it must be stated that research is iterative [30] and there is no guarantee that the project follows a linear process, i.e. a project may not start with a problem statement but with access to a dataset. The artefacts generated during a traditional IS research project are also generally the same. These can consist of problem statements; research questions; literature reviews; hypothesis; a research methodology; research protocols; unprocessed datasets; processed datasets; constructs; models; methods; frameworks; design principles; software; theories; some form of results dissemination (journal/conference articles, commentaries, media appearances); and reviews. What is not so rarely practiced is making any of these artefacts outputs of a research project other than when the academic article is written. That is to say, while they may or may not be produced, the focus of researchers is often more on publication priority, their career development, and financial concerns which is to the detriment of the overall scientific advancement.

Openness and free information sharing is supposed to be the norm of any science community, but this is not always practiced. Instead, researchers tend to prioritise the journal article at the end of their research project as this is currently the currency in which their careers are judged (often on the quality of the journal 
and the number of citations they receive which is also not an ideal situation) [13]. However, there is an opportunity to change this. A research output can be defined as "a particular dissemination, publication, presentation, communication or pathway in which research is made available to people other than the author" [27]. And as noted previously, there are many artefacts that a research project generates, all of which a researcher can consider making more open. But the question that needs to be answered is why should an IS researcher share any of these artefacts? This can be answered in the value it generates, from personal, discipline, and societal perspectives.

\subsection{The Value of Being More Open From An IS Researcher Perspective}

If we consider the three priorities introduced earlier (publication priority, career, and financial concerns), being more open can address each one.

5.1.1. Publication Priority. IS researchers have a strong tendency to focus on trying to publish articles in the basket of eight journals (and degrade gracefully from there). A motivating factor behind this is that institutions place a high priority on metrics such as journal impact factor [9] and citation count, to evaluate researchers (which are flawed metrics [9]). However, researchers are now facing an evolving landscape in terms of publications and the evaluation of research outputs [13]. It is our contention that this focus on the research article being the outcome of the project diminishes many other opportunities that researchers have to increase their outputs. No longer are they restricted to the academic paper at the end of a project but can instead increase the output of the work they put in. At the different stages of their project, researchers should ask themselves is this artefact, which we refer to as the open artefact [6] worth making available to the public. For example, when writing a problem statement and research questions, is it worth making this openly available where they can get feedback from their peers to make it a stronger artefact? A step further might even be to get feedback from the public who are interested in that research area. In doing so, not only can researchers strengthen the quality of their research but can also help to ensure it is worth doing while getting support behind it. For example, someone could indicate the research has already been done, or it is not actually a relevant problem worth solving.

This greatly changes the focus of the publication priority being on just academic journals but helps increase the research outputs of a researcher. Every time they make an artefact openly available, they receive a DOI for it. This is a permanent link to that artefact that can be shared with anyone. This greatly increases the possibility for proof-of-use opportunities for the research that is conducted. For example, IS practitioners often don't have an issue with the topics that IS researchers are researching but it is the accessibility of them that is the problem. Accessibility comes in two forms - first from literal access to journals/conferences, and second is they are not in the language and style they usually use, or providing the "how to" use the research. By being more open with the artefacts that are developed and sharing them on platforms where practitioners are likely to see them, IS researchers can increase the possibility of these practitioners to use their research. In turn, this can lead to the improvement of the impact of the research that they are conducting going beyond just the journal impact factor and citation count.

Further, practicing OS allows for research to be made available in a much timelier manner. This has never been truer than the recent impact of Covid-19, where IS researchers in general may not be able to add their expertise in a timely manner when trying to to study and publish their work on such an emerging issue. For example, Salman et al. [12] were able to make their research on an expert system they designed which allows doctors to detect and diagnose symptoms of coronavirus, which was made freely available on the AUG repository; and Zhou et al. [20] did the same with their work on the challenges to GIS and big data in relation to Covid-19. These instances allowed researchers not only to conduct research but make it freely available quickly, adding to the discussion. This would not have been possible under the current practices.

5.1.2. Career Development. Developing an academic profile is a difficult task. From the research aspect, it requires publications in top IS journals (reinforced by most academic positions requiring evidence of publishing in top IS journals or en route to doing so); and collaborations within and outside the institutions (both academic and practitioner orientated). While one of the ultimate goals to developing an IS academic profile should be on research impact, for now much focus is still on citation count as one metric for career development. However, as identified through the OA policy review, many of the journals indicate that by publishing articles as OA they can expect an increase in citations [9] (up to $32 \%$ for some [28]) and more downloads too $[28,29]$, thus increasing citations and exposure. Such an increase in interest in an author's publications helps to improve their academic profile.

Building on this, and referring to some of the discussion earlier, making different elements of your 
research openly available can also help build and improve your academic profile. As an example, the author of this paper recently had a successful promotion application which required them to list their publications and research outputs. These research outputs consisted of a number of possibilities including datasets, preprints, and open artefacts. As I have been practicing OS with most of my research projects, I was able to list 12 additional research outputs and include a DOI for each one. This allowed me to paint a far more realistic academic profile by showing the effort I have put in that would not be possible if I had not been practicing OS.

Practicing OA also greatly increases the opportunities for new projects and collaborations. Due to the exposure of the work being done and being able to share DOIs directly to it across different social media platforms, allows for greater opportunities that both practitioners and academics may access the work. Practitioners who see the work may be interested in collaborating on new projects that you may not have been exposed to before, and academics may see an opportunity to collaborate on a research project.

5.1.3. Financial Concerns. And lastly, a concern that is often raised is that the cost of publishing OA is an issue due to APCs [9]. As evidenced through the OA policy review here, this is not necessarily the case in terms of IS research. For example, the majority of journals provide authors with the opportunity to make a version of their manuscript freely available by selfarchiving in terms of green OA. That is they can often make different versions of their article available as OA on their personal website, institutional repository, and/or subject repository. However, as alluded to in the introduction, it is imperative that IS researchers begin to adopt such practices as they are the ones that are going to make the change happen [17]. They can also look to other ways of practicing OA by deciding to submit to OA journals, and also looking at making more elements of their research project artefacts available as open artefacts [6].

\section{Conclusion}

The traditional route of publishing an article and moving on to the next project is changing. This is evidenced by the fact that IS journals (and journals in general) are embracing OA by offering policies on how authors can share their articles. However, it is not the journals, funding schemes, libraries, universities, or governments, that will make this happen. Instead it is up to the authors themselves to do so. Authors of research articles get to decide where to submit their articles (to open access (OA) journals, non-open access journals, or hybrid journals); and decide whether to deposit their articles to an archive (personal; website, institutional repository, and/or a subject repository [17]. They also get to decide on what components of their research projects they share, which goes well beyond the academic article, and can result in many more valuable outputs.

One of the biggest barriers to authors adopting OA approaches is that it is currently not the norm to do so. However, as evidenced in the discussion above, there is a lot of value in incorporating it into our research. This includes increasing the opportunity for our research to be more impactful; allows us to increase our research outputs; often which can be done without a major financial burden to the author. Thus, we would encourage IS researchers to become more familiar with the practices of OA, apply it to a project they are currently working on, and eventually adopt it as a regular part of their research activity. Of course this is only one piece of the larger OS puzzle but it's certainly a step in the right direction to having a bigger impact on society.

\section{References}

[1] Beall, J., "Predatory publishers are corrupting open access", Nature 489(7415), 2012, pp. 179.

[2] Björk, B., M. Laakso, P. Welling, and P. Paetau, "Anatomy of green open access", Journal of the Association for Information Science and Technology 65(2), 2014, pp. 237-250.

[3] Björk, B., and D. Solomon, "How research funders can finance APCs in full OA and hybrid journals", Learned Publishing 27(2), 2014, pp. 93-103.

[4] Conte, S., "Making the choice: Open access vs. traditional journals", American Journal Experts, 2013. [5] van Deursen, A., "Green Open Access FAQ", https://avandeursen.com/2016/11/06/green-openaccess-faq/

[6] Doyle, C., M. Luczak-Roesch, and A. Mittal, "We Need the Open Artefact: Design Science as a Pathway to Open Science in Information Systems Research", International Conference on Design Science Research in Information Systems and Technology, Springer International Publishing (2019), 46-60.

[7] Grudniewicz, A., D. Moher, K.D. Cobey, et al., "Predatory journals: no definition, no defence", 2019. [8] Harnad, S., T. Brody, F. Vallières, et al., "The access/impact problem and the green and gold roads to open access: An update", Serials review 34(1), 2008, pp. 36-40.

[9] McKiernan, E.C., P.E. Bourne, C.T. Brown, et al., "Point of view: How open science helps researchers 
succeed", elife 5, 2016, pp. e16800.

[10] Piwowar, H., J. Priem, V. Larivière, et al., "The state of OA: a large-scale analysis of the prevalence and impact of Open Access articles", PeerJ 6, 2018, pp. e4375.

[11] Pontika, N., P. Knoth, M. Cancellieri, and S. Pearce, "Fostering open science to research using a taxonomy and an eLearning portal", Proceedings of the 15th International Conference on Knowledge Technologies and Data-driven Business, ACM (2015), 11.

[12] Salman, F.M., and S.S. Abu-Naser, "Expert System for COVID-19 Diagnosis”, 2020.

[13] Sarabipour, S., H.J. Debat, E. Emmott, S.J. Burgess, B. Schwessinger, and Z. Hensel, "On the value of preprints: An early career researcher perspective", PLoS biology 17(2), 2019, pp. e3000151. [14] Solomon, D.J., and B.-C. Björk, "A study of open access journals using article processing charges", Journal of the American Society for Information Science and Technology 63(8), 2012, pp. 1485-1495. [15] Suber, P., "Six Things That Researchers Need to Know about Open Access · Knowledge Unbound", 2019.

https://knowledgeunbound.mitpress.mit.edu/pub/2mnru gqa/release/1?readingCollection $=53 \mathrm{e} 63375$

[16] Suber, P., "SPARC Open Access Newsletter", 2008.

https://legacy.earlham.edu/ peters/fos/newsletter/0802-08.htm\#gratis-libre

[17] Suber, P., “'It's the Authors, Stupid!'”, 2019. https://knowledgeunbound.mitpress.mit.edu/pub/opn6a ocn/release/1

[18] Suber, P., and C. Kenneally, "“ Open Access,' The Book", Beyond the Book, 2012.

[19] Swan, A., and S. Brown, Open access selfarchiving: An author study, UK FE and HE funding councils, 2005.

[20] Zhou, C., F. Su, T. Pei, et al., "COVID-19:

Challenges to GIS with big data", Geography and
Sustainability, 2020.

[21] "SAGE's Author Archiving and Re-Use Guidelines | SAGE Publications Ltd", https://uk.sagepub.com/en-gb/eur/journal-authorarchiving-policies-and-re-use

[22] "Open Access Academy | Types of Open Access", http://www.oaacademy.org/types-of-open-access.html

[23] "Tutorial 19b: Open Access definitions and clarifications, part 2: Gold and Green | Sauropod Vertebra Picture of the Week", https://svpow.com/2012/11/16/tutorial-19b-openaccess-definitions-and-clarifications-part-2-gold-andgreen/

[24] "Green, hybrid or gold Open Access",

https://www.tue.nl/en/our-university/library/educationresearch-support/scientific-publishing/open-accesscoach/basic-concepts-and-background/green-hybridor-gold-open-access/

[25] "Copyright", https://en.wikipedia.org/wiki/Copyright

[26] "Licensing FAQ - OASPA", https://oaspa.org/information-resources/frequentlyasked-questions/

[27] "Research Definition and Research Outputs: System Categorisation Guidelines - The University of Auckland", https://www.auckland.ac.nz/en/about/theuniversity/how-university-works/policy-andadministration/research/output-system-andreports/research-outputs--definition-andcategories.html

[28] "Submit to European Journal of Information Systems", https://www.tandfonline.com/action/authorSubmission ?show $=$ instructions \&journalCode $=\mathrm{tjis} 20 \#$ oa [29] "FAQs | SAGE Publications Ltd", https://uk.sagepub.com/en-gb/eur/faqs [30] How science works, 2012. 